\title{
PERFORMANCE EVALUATION OF HIGH-TEMPERATURE SUPERCONDUCTING CURRENT LEADS FOR MICRO-SMES SYSTEMS*
}

\author{
R. C. Niemann, Y. S. Cha, J. R. Hull \\ Argonne National Laboratory, Argonne, Ilinois 60439 \\ W. E. Buckles, B. R. Weber \\ Superconductivity, Inc., Middleton, Wisconsin 53705 \\ S. T. Yang \\ University of Wisconsin, Madison, Wisconsin 53706
}

\section{DISCLAIMER}

\begin{abstract}
This report was prepared as an account of work sponsored by an agency of the United States Government. Neither the United States Government nor any agency thereof, nor any of their employees, makes any warranty, express or implied, or assumes any legal liability or responsibility for the accuracy, completeness, or usefulness of any information, apparatus, product, or process disclosed, or represents that its use would not infringe privately owned rights. Reference herein to any specific commercial product, process, or service by trade name, trademark, manufacturer, or otherwise does not necessarily constitute or imply its endorsement, recommendation, or favoring by the United States Government or any agency thereof. The views and opinions of authors expressed herein do not necessarily state or reflect those of the United States Government or any agency thereof.
\end{abstract}

The submitted manuscript has been authored
by a contractor of the U. S. Government
Under contract No. W-31-109-ENG-38.
Accordingly, the U. S. Government retains a
nonexclusive, royally-free icense to publish or
reproduce the pubilshed form of this
contribution, or allow others to do so, for U.S.
Government purposes.

For presentation at 1995 Cryogenic Engineering Conference, July 17-21, 1995, Columbus, $\mathrm{OH}$.

*Work partially supported by the U.S. Department of Energy, Energy Efficiency and Renewable Energy, as part of a program to develop electric power technology, under Contract W-31-109-Eng-38, and by Superconductivity, Inc., Middleton, WI, USA. 


\section{DISCLAIMER}

Portions of this document may be illegible in electronic image products. Images are produced from the best available original document. 


\title{
PERFORMANCE EVALUATION OF HIGH- TEMPERATURE SUPERCONDUCTING CURRENT LEADS FOR MICRO-SMES SYSTEMS
}

\author{
R. C. Niemann, ${ }^{1}$ Y. S. Cha, ${ }^{1}$ J. R. Hull, ${ }^{1}$ W. E. Buckles, ${ }^{2}$ B. R. Weber, ${ }^{2}$ \\ and S. T. Yang 3 \\ 1 Argonne National Laboratory \\ Argonne, IL 60439, USA \\ ${ }^{2}$ Superconductivity, Inc. \\ Middleton, WI 53705, USA \\ 3 University of Wisconsin \\ Madison, WI 53706, USA
}

\begin{abstract}
As part of the U.S. Department of Energy's Superconductivity Technology Program, Argonne National Laboratory and Superconductivity, Inc., are developing high-temperature superconductor (HTS) current leads for application to micro-superconducting magnetic energy storage systems. Two 1500-A HTS leads have been designed and constructed. The performance of the current lead assemblies is being evaluated in a zero-magnetic-field test program that includes assembly procedures, tooling, and quality assurance; thermal and electrical performance; and flow and mechanical characteristics. Results of evaluations performed to date are presented.
\end{abstract}

\section{INTRODUCTION}

A superconducting magnetic energy storage (SMES) system stores electrical energy to provide power during voltage sags and momentary power losses. SMES devices store electric energy as a circulating current in a magnetic coil; because superconducting coils offer virtually no resistance to the current, they are far more efficient than normal conducting coils, achieving overall energy conversion efficiencies of $>95 \%$. In addition, these devices have very high response rates and contain no internal moving parts, so they are highly reliable and promise long service life.

HTS current leads are particularly advantageous for SMES devices because they have the potential to reduce refrigeration requirements to values significantly below the best values achievable with conventional leads. 
As part of the U.S. Department of Energy's Superconductivity Technology Program, Argonne National Laboratory is developing, with Superconductivity, Inc. (SI), HTS current leads suitable for micro-SMES applications.

Superconductivity, Inc., is engaged in the design, construction, operation, and commercial sales of micro-SMES systems for application in the power-quality market. 1 This application requires relatively low energy storage and comparatively high power delivery. Units store $\approx 1 \mathrm{MJ}$ and are able to discharge at a rate of $1 \mathrm{MW}$. The integrated system is factory-built for low cost and consistent quality and is transportable overland.

The economic justification for SI's system is not based on the cost of the energy stored in the unit, but on the value of avoiding an interruption of the power supply. The cost of shutdowns due to sags and outages has been estimated to be in the billions of dollars per year in the U.S. alone. While long-term outages have been effectively reduced by electric utilities, momentary voltage disturbances have actually increased in many power systems across the country. At the same time, many industries have dramatically expanded their use of electronically controlled equipment, which is particularly sensitive to momentary voltage disturbances. These two factors have resulted in an increased need for quality power in many segments of the economy.

\section{PERFORMANCE SPECIFICATIONS FOR CURRENT LEAD}

The current lead installation geometry is shown in Fig. 1, and major performance requirements are given in Table $1 .^{2}$

\section{CURRENT LEAD DESIGN}

\section{General Arrangement}

The general arrangement of the current lead is shown in Fig. 2. Major subassemblies are the conventional upper stage, the transition assembly, and the HTS lower stage.

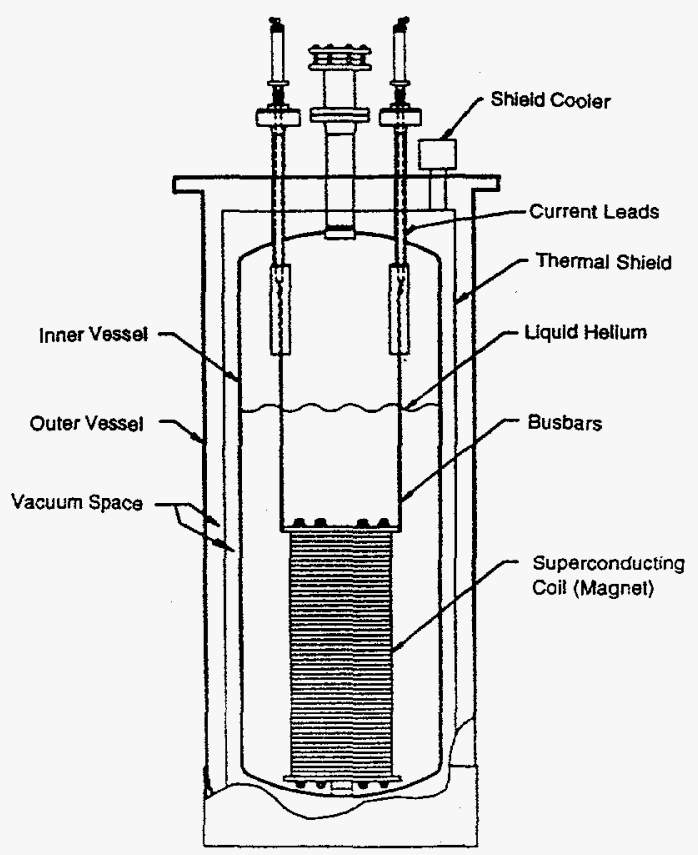

Figure 1. Current lead installation geometry. 
Table 1. Major performance requirements for HTS current leads.

\begin{tabular}{ll}
\hline \multicolumn{1}{c}{ Parameter } & \multicolumn{1}{c}{ Design value } \\
\hline $\mathrm{I}_{\mathrm{Op}}, \mathrm{V}_{\max }, \mathrm{B}_{\max }$ & $1.5 \mathrm{kA}, 7.5 \mathrm{kV}, \mathrm{SMES}+$ self \\
Dimensions & $0.1 \mathrm{~m}$ diam. $1 \mathrm{~m}$ length \\
HTS Temperature & $\mathrm{T}_{\text {warm }} \leq 60 \mathrm{~K}, \mathrm{~T}_{\text {cold } \cong 10 \mathrm{~K}}$ \\
Heat leakage @ $4 \mathrm{~K}$ & $<0.7 \mathrm{~W} /$ lead \\
$300-60 \mathrm{~K}$ cooling & Helium gas + refrigerated intercept \\
$60-10 \mathrm{~K}$ cooling & Helium gas + conduction \\
\hline
\end{tabular}

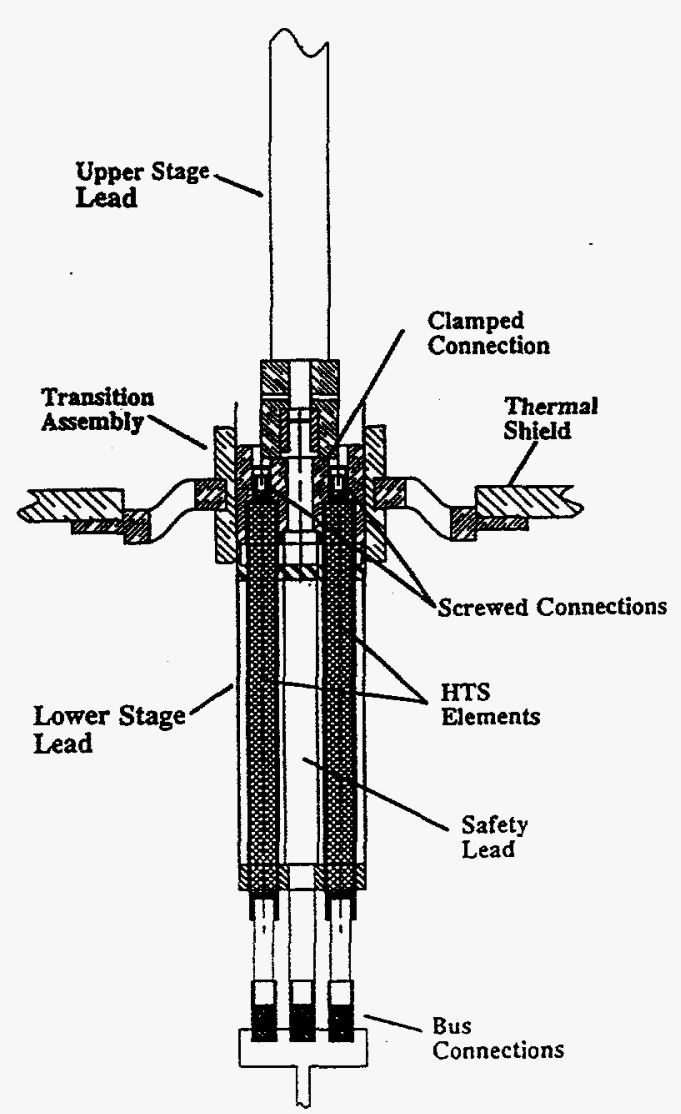

Figure 2. General arrangement of current lead.

\section{Conventional Upper Stage}

The design parameters of the upper stage include a 1500-A operating current; warm- and cold-end temperatures of 300 and $60 \mathrm{~K}$, respectively; and helium-vapor flow equivalent to $1.2 \mathrm{~L} / \mathrm{hr}$ per lead. Estimated heat leakage to $60 \mathrm{~K}$ is $47 \mathrm{~W}$ per lead. The upper stage was designed and constructed by a commercial vendor.

\section{Transition Assembly}

The transition assembly provides electrical and mechanical connections between the lower and upper stages, flow paths for the helium-vapor cooling stream, a heat intercept connection to a cryocooler, electrical isolation between the lead and the adjacent cryostat components, and pressure vessel continuity within the cryostat. The geometry, materials, and methods of fabricating the transition assembly are selected to minimize the temperature 
difference between the warm end of the HTS element and the cryocooler intercept. The transition assembly must also provide effective and reliable electrical isolation, i.e., very low leakage current and high voltage standoff. 3,4

\section{HTS Lower Stage}

The lower stage consists of six parallel current-carrying YBCO HTS rods containing 15 vol.\% silver. The rods, $1.3 \mathrm{~cm}$ in diameter and $20 \mathrm{~cm}$ long, are connected to the transition assembly at their warm ends and to the bus collector assembly at their cold ends. Each rod is enclosed in an epoxy/fiberglass tube that channels the helium-vapor coolant and provides structural support for the rod. A safety lead is in the center of the HTS rod array. The estimated heat leakage to $4 \mathrm{~K}$ is $0.9 \mathrm{~W}$ per lead.

A safety lead is incorporated in the lower-stage assembly as an alternate current path in the event of HTS malfunction. The safety lead consists of a stainless steel tube connected in parallel with the conductor elements.

The lower ends of the six HTS elements are connected to a bus collector by six lowtemperature superconductor (LTS) composite elements. The collector is connected to the terminal of the magnet coil by LTS buswork. Voltage isolation along the length of the lead is provided by epoxy/fiberglass composite tubing that surrounds the lead elements.

\section{CONSTRUCTION OF CURRENT LEADS}

\section{Conductor Elements}

The YBCO conductor elements incorporate silver-painted and sintered end caps, which were joined to the gold-plated copper warm and cold end caps with $60 / 40 \mathrm{Sn} / \mathrm{Pb}$ solder.

The critical currents of the HTS rods were measured at $77 \mathrm{~K}$. The critical current for the 12 rods ranged from $215 \mathrm{~A}$ to $250 \mathrm{~A}$. The rods were divided into two balanced groups, one for each lead, based on their $77 \mathrm{~K}$ critical currents. The rods in a group were then azimuthally oriented to minimize the effects of the SMES magnet's fringe field on the current-carrying capacity of the rods.

To reduce the effects of atmospheric moisture on the HTS material, shrinkable Mylar tubing was applied over the HTS rods. The small gap between the Mylar tubing and each end cap was sealed with a coating of Shell 820/Versamid 140 epoxy. An epoxy/fiberglass tube was then installed over the HTS rod. The tube was bonded to the warm end cap and allowed the cold end cap to slide in order to accommodate differential thermal movement.

Because final assembly of the current leads was delayed for $\approx 1$ year due to human resource availability, and because during that period the rods were exposed to a nonhumidity-controlled environment, it was decided to remeasure the critical currents. The $77 \mathrm{~K}$ critical currents ranged from $214 \mathrm{~A}$ to $282 \mathrm{~A}$. This demonstrated the effectiveness of the humidity-proofing measures employed.

The conductor element assemblies, i.e., HTS rod, end caps, and reinforcing, surrounding epoxy fiberglass tube, proved to be structurally robust, having survived repeated 300-to-77-to-300 $\mathrm{K}$ thermal cycling, common carrier shipments, and the handling of two assemblies and one disassembly.

\section{Upper Stage - Transition Assembly}

The upper stage and the transition assembly were assembled by a clamped connection. The clamped members were gold-plated copper and incorporated an indium gasket at their interface. ${ }^{5}$ Clamping was achieved with a torqued bolt and conical spring washers that were used to maintain the bolt load. 
Transition Assembly - Lower Stage

The conductor elements were connected to the transition assembly by gold-platedcopper screwed connections. 5 The conductor elements-transition assembly is shown in Fig. 3. The safety lead and the low-temperature superconductor cold end transitions were installed. The current lead assembly is shown in Fig. 4.

\section{High-Voltage Isolation}

After installation of voltage and temperature sensors, high-voltage isolation members in the form of epoxy/fiberglass tubing were installed.

\section{OPERATION IN ZERO MAGNETIC FIELD}

\section{Objectives}

A program of system performance evaluation has been developed to evaluate the performance of the current lead assemblies. The test program objectives include evaluation of thermal performance, including heat leakage, temperature distribution, steady-state and upset response, and shield cooler performance effects; electrical performance, including voltage drops, voltage isolation, upset conditions, safety lead, and lead-to-lead differences; flow characteristics, including pressure drop vs. mass flow rate, voltage drop vs. mass flow rate, voltage drop vs. inlet temperature, and lead-to-lead differences; and mechanical characteristics, including thermal contraction, HTS rod strain, upset conditions, and stiffness of upper- and lower-end connections.

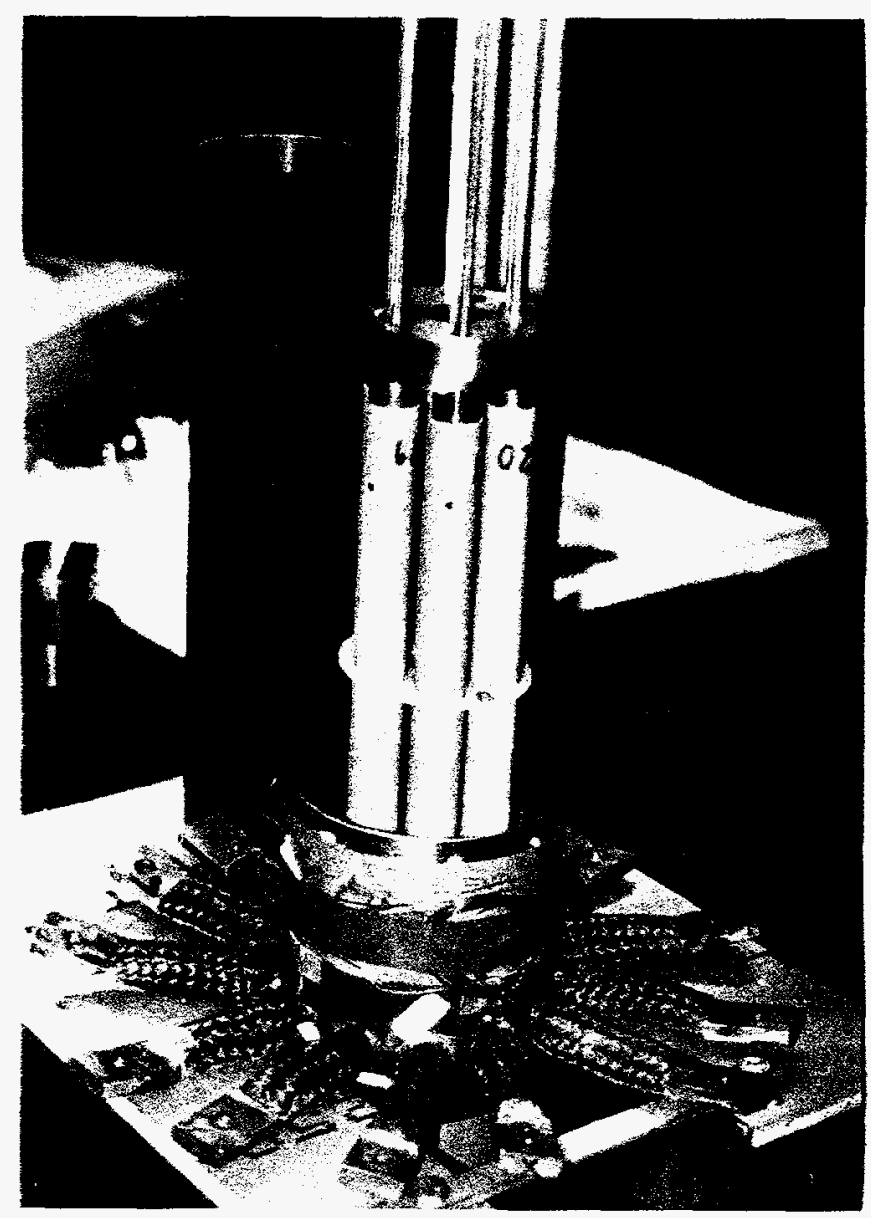

Figure 3. Conductor elements-transition assembly. 


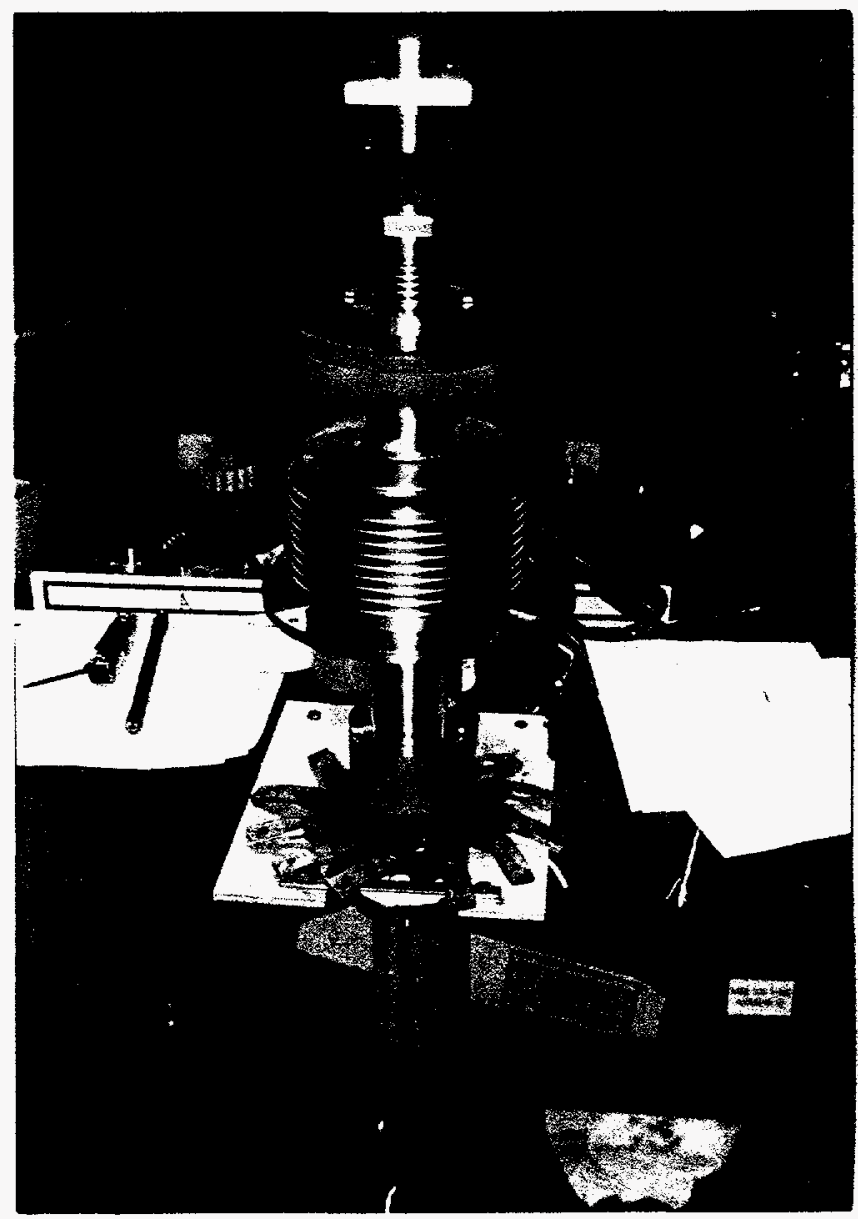

Figure 4. Current lead assembly.

\section{Test Program}

Evaluations are performed in a liquid-helium test cryostat as shown in Fig. 5. Upperstage (heat meter) and lower-stage (boil-off) heat leakage values are calculated from test data. Measured electrical values include upper-stage, transition assembly, rod, and collector assembly voltage drops. Tests are planned for several steady-state and upset conditions, as shown in Table 2. The test program includes runs at reduced cryocooler capacity and elevated cooling-gas inlet temperature.

\section{Initial Operation}

The integrated performance measurement system has been initially operated to evaluate operational readiness. The liquid helium and liquid nitrogen vessels and piping were leaktight during cryogenic operations. The cryocooler is functional and provides effective shield and intercept cooling. Cryostat external insulating vacuum feedthroughs were found to be temperature-sensitive and require corrective measures. Instrumentation and data acquisition system are functional, as is the power supply system.

The integrated system has been operated at lead currents to $1150 \mathrm{~A}$ during checkout of the measurement system. 


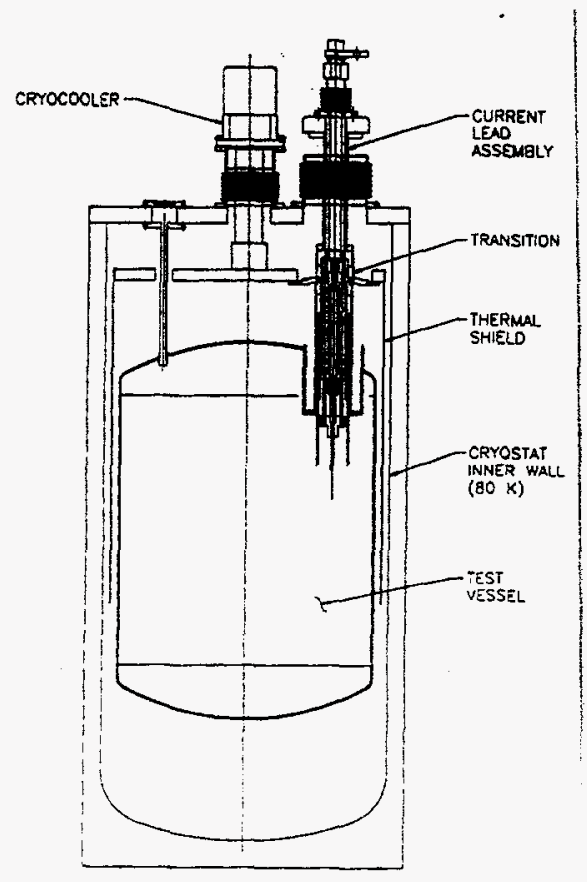

Figure 5. Liquid-helium test cryostat.

Table 2. Steady-state and upset thermal and electrical tests.

\begin{tabular}{|c|c|c|c|}
\hline $\begin{array}{l}\text { Measured } \\
\text { quantity }\end{array}$ & Current & $\begin{array}{l}\text { Lead gas } \\
\text { flow }\end{array}$ & $\begin{array}{l}\text { Cryocooler } \\
\text { status }\end{array}$ \\
\hline Zero current heat leakage & 0 & Unrestricted & On \\
\hline $\begin{array}{l}\text { Nonzero current heat } \\
\text { leakage }\end{array}$ & $\begin{array}{l}25-100 \% \text { of } \\
\text { design }\end{array}$ & Unrestricted & On \\
\hline Zero flow current & $\begin{array}{l}50-100 \% \text { of } \\
\text { design }\end{array}$ & Off & On \\
\hline $\begin{array}{l}\text { Zero current, zero cryo- } \\
\text { cooler heat leakage }\end{array}$ & 0 & Unrestricted & Off \\
\hline $\begin{array}{l}\text { Nonzero current, zero } \\
\text { cryocooler heat leakage }\end{array}$ & $\begin{array}{l}75-100 \% \text { of } \\
\text { design }\end{array}$ & Unrestricted & Off \\
\hline Loss of flow upset & $\begin{array}{l}25-100 \% \text { of } \\
\text { design }\end{array}$ & $\begin{array}{l}\text { Unrestricted } \\
\text { to off }\end{array}$ & On \\
\hline Loss of cryocooler upset & $\begin{array}{l}25-100 \% \text { of } \\
\text { design }\end{array}$ & Unrestricted & On to off \\
\hline
\end{tabular}

\section{OPERATION WITH CURRENT}

Initial operation with current was at the $600 \mathrm{~A}$ level. The intermediate temperature intercept, i.e., HTS conductor element warm end, was operated at $45 \mathrm{~K}$ and $55 \mathrm{~K}$. Lead flow was varied from $100 \%$ to $30 \%$ of the total flow, i.e., lead flow plus dewar flow.

The cryostat inner vacuum wall failed by buckling during a pumpdown and purge operation preceding the $900 \mathrm{~A}$ test run. The balance of the testing will be performed in another cryostat. Preparations for the conversion are underway. 


\section{CONCLUSIONS}

- Two of 1500-A HTS current leads for micro-SMES application have been constructed.

- Each lead employs a parallel cylindrical array of six 1.3-cm-OD x 20-cm-long YBCO w/15 vol.\% Ag sintered HTS conductor elements. The average measured critical current was 234 A@77 K@0.005 T applied field.

- Demountable connections join the conventional upper stage lead to the HTS lower stage lead. Both clamped and screwed connections are employed and result in an apparent joint resistivity of $\leq 1.8$ that of the base material (ETP copper) at modest assembly torques.

- Heat intercepting is via a transition assembly that provides an electrically isolating and thermally effective connection. The measured $\Delta \mathrm{T}$ for a prototype assembly across the insulator is $\approx 12 \mathrm{~K} @ 45 \mathrm{~W}$ heat flow @ $70 \mathrm{~K}$ operating temperature.

- The transition assembly cables have been calibrated as heat meters to allow measurement of the heat load to the transition intercept.

- The lead pair is undergoing electrical, thermal, and structural evaluations under simulated operating conditions. The integrated measurement system has been operated to evaluate functional readiness. The leads have been initially operated at currents to $1150 \mathrm{~A}$. Performance has been evaluated at $600 \mathrm{~A}$. Further testing at higher currents has been delayed by a failure in the test cryostat.

\section{ACKNOWLEDGMENTS}

The authors gratefully acknowledge the engineering contributions of M. A. Daugherty; the technical expertise of M. Bordson, D. J. Evans, A. S. Wantroba, and K. Ziemer; the manuscript preparation skills of J. A. Stephens; and the editorial contributions of C. A. Malefyt. Work at ANL was supported by the U.S. Department of Energy, Energy Efficiency and Renewable Energy, as part of a program to develop electric power technology, under Contract W-31-109-Eng-38. Work at Superconductivity, Inc., was conducted as a part of the corporation's internal-systems development program.

\section{REFERENCES}

1. W.E. Buckles, M.A. Daugherty, B.R. Weber, and E.L. Kostecki. The SSD: a commercial application of magnetic energy storage, IEEE Trans. Appl. Supercond. 3:328 (1993).

2. R.C. Niemann, Y.S. Cha, J.R. Hull, W.E. Buckles, and M.A. Daugherty. Engineering design of a hightemperature superconductor current lead, in Supercollider 5, P. Hale, ed., Plenum Press, New York (1994), pp. 629-634.

3. R.C. Niemann, J.D. Gonczy, T.H. and Nicol. 1994c, Low-thermal-resistance, high-electrical-isolation heat intercept connection, in Advances in Cryogenic Engineering, Plenum Press, New York, Vol. 39 (1994), pp. 1665-1673.

4. R.C. Niemann, J.D. Gonczy, and T.H. Nicol, Thermally effective, electrically isolating heat intercept connections, in Thermal Engineering 1995, Vol. 1, L. S. Fletcher and T. Aihara, eds., ASME, New York, (1995), pp. 43-50.

5. R.C. Niemann, Y.S. Cha, J.R. Hull, W.E. Buckles, M.A. and Daugherty. Performance evaluations of demountable electrical connections, in Advances in Cryogenic Engineering, Plenum Press, New York, Vol. 39 (1994), pp. 1153-1160. 